\title{
Mechanism Modeling and Parameters Identification of Pneumatic Booster Mass Flow
}

\author{
Xiaohuan Pei, Qunli Shang*, Kaibin Wang and Pengfei Li \\ Zhejiang University of Technology, Hangzhou 310023, China \\ ${ }^{*}$ Corresponding author
}

\begin{abstract}
Pneumatic amplifier is not only the commonly used independent electrical attachment but also one of key components of the valve positioner. In this paper, a mass flow mechanism model of the typical pneumatic amplifier is established, and the method of parameter identification is proposed. Firstly, according to the working principle and structural characteristics of the pneumatic amplifier, the mass flow model of the pneumatic amplifier is established by using the principle of thermodynamics and fluid mechanics. Secondly, a new sub model is established for the important equivalent orifice area by the experimental study, and the parameter identification is carried out. Finally, the model is verified by the experimental platform of the control valve. The results show that the accuracy of the model is up to $90 \%$ compared with the actual typical pneumatic amplifier.
\end{abstract}

Keywords-pneumatic amplifier; mechanism modeling; parameter identification; control valve experimental platform

\section{INTRODUCTION}

In the industrial flow control process, intelligent control valves are required to have higher accuracy, rapidity and reliability. Pneumatic amplifier (or pneumatic accelerator) is not only the commonly used independent electrical accessory of control valve, but also one of the key components of the control valve positioner. Establishing an accurate mass flow model of the amplifier is a key step to improve the control valve simulation model. Establishing an accurate mass flow model of the pneumatic amplifier is a key step to improve the control valve simulation model. Accurate and complete control valve model is the foundation for the study of control valve design (mechanics and pneumatic path), control system algorithms, performance evaluation, fault diagnosis and so on.

In recent years, many scholars at home and abroad have been researching on control valve simulation model. Literature [1-3] belongs to the theory of modeling, by simplifying the hypothesis, setting up the control valve force balance then we get the mathematical model of the control valve. The model of pneumatic position servo system is analyzed by literature [4]. The system of nonlinear differential equations is obtained, but some parameters such as friction force are difficult to be measured, so there are some errors in modeling. In literature [5], the dynamic modeling of pneumatic system can be regarded as a typical kind of components (or modules), which provides the idea of the modular modeling. In this paper, according to the fundamental conservation law of gas movement process, the state parameters of the gas meet the functional relationship of the thermodynamic properties of the gas, and the mass flow model of the pneumatic amplifier is proposed. This article firstly proposed equivalent model of equivalent restriction area of the orifice in gas mass flow model and carry out parameter identification for this new model, to further improve the control valve simulation model.

\section{MEChANism MODEL OF MASS Flow In PNEUMATIC AMPLIFIER}

According to the typical structure and working principle of the pneumatic amplifier, it is equivalent to a direct seat regulating valve and adjustable orifice flow physical model. The mass flow mathematical model of pneumatic amplifier is established based on the principle of thermodynamics and fluid mechanics. And obtain the equivalent mathematical model of mass flow throttling area of pneumatic amplifier the important parameters of the model by experimental study.

\section{A. The Structure and Working Principle of Pneumatic Amplifier}

This article take the pneumatic amplifier of the smart valve positioner which is commonly used on the market as an example. The main purpose of pneumatic amplifier is to change the micro displacement in the nozzle baffle mechanism into the change of pressure and power amplification. Its structure is shown below in Figure I:

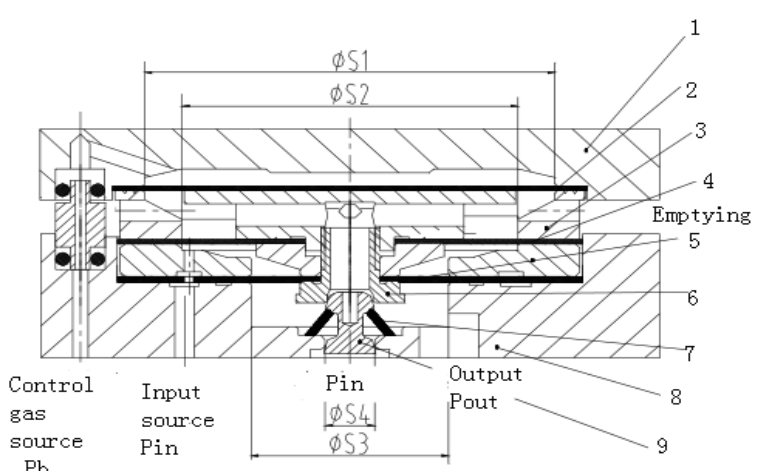

FIGURE I. STRUCTURE DIAGRAM OF PNEUMATIC AMPLIFIER

In Figure I 1 is the screw connection, 2 is the upper chamber lid, 3 is the upper diaphragm, 4 is the discharge device, 5 is the middle diaphragm, 6 is the under diaphragm, 7 is the exhaust valve seat, 8 is the reset, 9 is the lower chamber lid, 10 is valve spool. 
Amplifier consists of the upper diaphragm, the exhaust devices, the middle diaphragm, the under diaphragm, the exhaust valve seat, the return spring members, the spool, which are successively loaded into the lower chamber lid. Then connect the lower chamber to the upper cavity cover by screw. The force provided by the reset elastic members is so small compared to the air pressure, the film chamber pressure and the gas source that it merely push spool reset.

Control air pressure ( $P_{b}$,also called back pressure) by controlling the air supply channel comes into the interior of the pneumatic amplifier, producing a downward force on the upper diaphragm. Air source pressure $\left(P_{S}\right)$ enters into the pneumatic amplifier inside by the channel of input gas source, which produces a upward force on the middle diaphragm. Film

chamber pressure and the output port

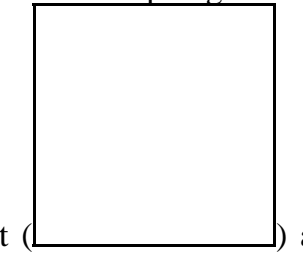

connected, and produces an upward force on the lower diaphragm. In the operation, the direction of the external force generated by the three diaphragm of the pneumatic amplifier determines that the intelligent positioner is in the air intake or exhaust state. Its working process is divided into an exhaust state, no intake-no exhaust state and intake state.

When in the intake state, air pressure enters into amplifier through input air channel, and inputs to the film gas chamber through the output channel. While in exhaust state, the film chamber pressure enter the pneumatic amplifier through output channel and then discharged to the atmosphere through the evacuation port. According to the working principle of the amplifier, the size of the external force is $F=P_{b} S_{1}-\left(P_{\text {out }} S_{3}+P_{\text {in }}\left(S_{2}-S_{3}\right)\right)$, the positive and negative of this external force determines the pneumatic amplifier is in the air or exhaust state [6-8]. $S_{1}$ is the effective cross-sectional area of the upper diaphragm, $S_{2}$ is the effective cross-sectional area of the middle diaphragm, $S_{3}$ is the effective crosssectional area of the lower diaphragm, these parameters can be obtained through the specific pneumatic amplifier model. According to the working principle of the pneumatic amplifier, it can be equivalent to a two-seat control valve, which one is a set of intake, and another is exhaust group, and they are both linkage with. The force exerted in each diaphragms together was referred to as the combined force $(F)$, and the intake or the exhaust gas mass size in unit time was referred to as mass flow.

\section{B. Mass Flow Model}

The charge and discharge process of amplifier can be equivalent to a small whole flow characteristics, which is divided into sonic state and subsonic flow state. When the upstream pressure named P1 of orifice remains constant, gas mass flow $q$, through the orifice will increase while the downstream pressure named P2 decreases. When the downstream pressure named $\mathrm{P} 2$ reduced to a certain extent and continues to decrease, its mass flow rate does not continue to increase but become saturated. This is because the air flow through the orifice downstream reaches the speed of sound, causing the information of pressure drop cannot be transmitted to the upstream. At this point the gas flow speed is called sonic flow, which is also known as choked. Flow without saturation state called subsonic gas flow stream [9]. When passing through the hole, air has a small contact area with the pipe wall and the flow rate is at a high speed, so it can be equivalent to a one-dimensional isentropic flow which is indicated in literature [10].Thus, according to Bernoulli's equation, the flow velocity named $u_{2}$ was formulated at the orifice by the following:

$$
u_{2}=\sqrt{\frac{2 k}{k-1} * \frac{P_{1}}{\rho_{1}} *\left[1-\left(\frac{P_{2}}{P_{1}}\right)^{\frac{k-1}{k}}\right]}
$$

where $k$ represents the specific heat of air and $\rho_{1}$ represents upstream of the orifice for the air density. Since the speed of orifice air is very high and it has very little heat exchange with the outside air, it can be substituted into equation adiabatic process, and the gas mass flow through the orifice can be expressed as:

$$
\begin{aligned}
q & =S_{e} \rho_{2} u_{2} \\
& =S_{e} P_{1} * \sqrt{\frac{2 k}{k-1} \frac{1}{R T_{1}}\left[\left(\frac{P_{2}}{P_{1}}\right)^{\frac{2}{k}}-\left(\frac{P_{2}}{P_{1}}\right)^{\frac{k+1}{k}}\right]}
\end{aligned}
$$

Where $S_{e}$ is the equivalent orifice restriction area, $\rho_{2}$ is the orifice downstream air density, $R$ is the gas constant, $T_{1}$ is the temperature of the air upstream of the orifice.

When the gas mass flow reaches saturation, it will be in a speed of sound flow state, the than of the upstream pressure and the downstream pressure is the critical pressure ratioat this time. According to equation (1), the condition of gas mass flow rate reaching the maximum availability can set up following formula, where $\mathrm{K}$ is 1.4 :

$$
b=\left(\frac{P_{2}}{P_{1}}\right)^{*}=\left(\frac{2}{k+1}\right)^{\frac{k}{k-1}}=0.5283
$$

When the critical pressure ratio is substituted into the formula (2.1), sonic flow can be obtained, that is the gas mass flow rate under saturated state:

$$
q=S_{e} P_{1} \sqrt{\frac{k}{R T_{1}} *\left(\frac{2}{k+1}\right)^{\frac{k+1}{k-1}}}
$$


According to equation (1) and equation (2), the mass flow rate when the gas through the throttle holes can be obtained as follows:

$$
q=S_{e} P_{1} \frac{\phi}{\sqrt{T_{1}}}
$$

Where in the case of $\frac{P_{2}}{P_{1}} \leq 0.5283$, then $\phi=\sqrt{\frac{k}{R}\left(\frac{2}{k+1}\right)^{\frac{k+1}{k-1}}}$.

Where in the case of $\frac{P_{2}}{P_{1}}>0.5283$,

then $\phi=\sqrt{\frac{2 K}{K-1} \frac{1}{R}\left[\left(\frac{P_{2}}{P_{1}}\right)^{\frac{2}{K}}-\left(\frac{P_{2}}{P_{1}}\right)^{\frac{K+1}{K}}\right]}$.

$\phi$ stream of sound velocity is constant, and it is represented by $K_{G}$, as

$$
\phi_{\text {sonic }}=K_{G}=\sqrt{\frac{k}{R}\left(\frac{2}{k+1}\right)^{\frac{k+1}{k-1}}}=0.04043
$$

Calculation of subsonic flow is more complex, and it is related to a function $P_{2} / P_{1}$, According to subsonic flow curve defined by ISO / 6358 which is indicated in literature [11], the approximate expression of the subsonic flow named $\phi$ is as follows:

$$
\phi_{\text {subsonic }}=K_{G} \sqrt{1-\left(\frac{\frac{P_{2}}{P_{1}}-b}{1-b}\right)^{2}}
$$

Finally, the $\phi$ is substituted into the formula (3) and the mass flow of gas through the throttle hole is divided into two situations: when $b \geq P_{2} / P_{1}$, then mass flow rate under velocity of sound flow as follows:

$$
q_{m}^{*}=0.04 \frac{P_{1}}{\sqrt{T_{1}}} S_{e}
$$

when $P_{2} / P_{1}<b \leq 1$, the mass flow of subsonic flow is as follows:

$$
q_{m}=q_{m}^{*} \sqrt{1-\left(\frac{\frac{P_{2}}{P_{1}}-b}{1-b}\right)^{2}}
$$

Where $q_{m}^{*}$ represents the gas mass flow rate is at velocity of sound, $q_{m}$ represents the gas mass flow rate is at subsonic, $P_{1}$ represents the pressure upstream of the orifice, $P_{2}$ represents the downstream pressure of the orifice, $T_{1}$ represents the upstream air temperature of the orifice, $S_{e}$ represents the orifice equivalent throttle area, $b$ represents the critical pressure ratio.

\section{Equivalent Throttle Area Model}

Equivalent orifice throttle area within gas mass flow model cannot be directly described by mathematical expressions, and it is difficult to obtain accurate measurements by specific tools or methods. Therefore, it is necessary for equivalent orifice throttle area to create a new model.

1) Experimental principle introduction. Firstly, according to the flow curve, if the pressure in the valve is fixed, the relationship between flow rate and the valve position will be determined by the shape of the valve spool. Depending on the shape of the valve spool, there are linear flow characteristics, equal percentage flow characteristics, and the size of the valve position is determined by the force which is indicated in literature [12,13]. Observing the equivalent control valve two-seat spool of pneumatic amplifier shows that it is linear shape. So we have reason to suspect that the combined force that valve stem suffered has a linear relationship with the flow. Among them, the combined force produced by the equivalent control two-seater spool of pneumatic amplifier is equivalent to each diaphragm force(F) together. This combined force can effectively describe by specific model, and the accuracy of this conclusion will be is verified by following experiments.

Secondly, according to the gas mass flow model of sound velocity flow formula $q_{m}^{*}=0.04\left(P_{1} / \sqrt{T_{1}}\right) S_{e}$, reveals that when the upstream pressure in the pores $\left(P_{1}\right)$ determined, there is a linear relationship between gas mass flow $\left(q_{m}^{*}\right)$ through pneumatic components and equivalent throttling $\operatorname{area}\left(S_{e}\right)$.

2) Experimental design. The experimental purpose: to verify that gas mass flow $\left(q_{m}^{*}\right)$ of through the pneumatic components and the total force ( $F$ )produced each of the diaphragms of pneumatic amplifier are linear.

The experimental equipment: pneumatic amplifier valve core is divided into the inlet valve core and the exhaust valve core, the principle and experiment steps of air input and output are alike. To be convenient for research, simplify the pneumatic amplifier as the equipment shown in the below figure II, which is double valve core structure. This paper studies the pneumatic amplifier in its intake state. 


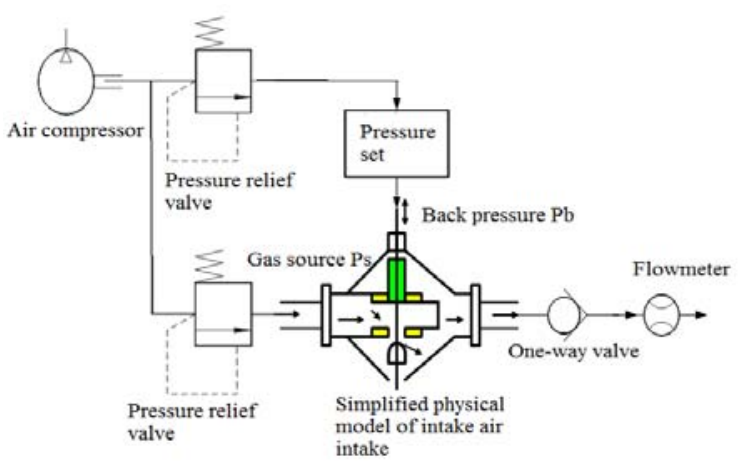

FIGURE II. SIMPLIFIED BLOCK DIAGRAM OF THE AMPLIFIER

Experiment description: when the upstream pressure $\left(P_{1}\right)$ is determined, giving different backpressure $\left(P_{b}\right)$, the gas mass flow of pneumatic components can be measured by the measurement of flow meter. According to the working principle of the pneumatic amplifier, recording the combined force as $F=P_{b} S_{1}-\left(P_{\text {out }} S_{3}+P_{\text {in }}\left(S_{2}-S_{3}\right)\right)$, the positive and negative direction of the combined force decide that the pneumatic amplifier is in the state of the intake or exhaust. where $S_{1}$ represents the effective area of the upper diaphragm, $S_{2}$ represents the effective area of the middle diaphragm , $S_{3}$ represents the effective area of the under diaphragm, those parameters can be measured by specific pneumatic amplifier models. In this paper, based on Yamatake AVP200 series positioner, $S_{1}=13.52 \mathrm{~mm}^{2}, S_{2}=9.28 \mathrm{~mm}^{2}, S_{3}=3.14 \mathrm{~mm}^{2}$ can be obtained. Due to the gas flowing through pneumatic components flows into the atmosphere, whose value is $101.3 \mathrm{Kp}$, the value of Pout is thought as a standard atmospheric pressure. So each of the back pressure values $\left(P_{b}\right)$ can determine the resultant force value ( $F$ ), and the relationship between the gas mass flow and the combined force.

Experimental procedures: firstly, when air pressure $\left(P_{i n}\right)$ is fixed, setting a back pressure $\left(P_{b}\right)$, measure and record the gas mass flow value $\left(q_{m}^{*}\right)$ at the current backpressure by a flow meter .

Secondly, keep the air pressure value $\left(P_{\text {in }}\right)$, increasing the value of back pressure $\left(P_{b}\right)$, then measure and record the corresponding gas mass flow value $\left(q_{m}^{*}\right)$, until such time as the back pressure $\left(P_{b}\right)$ continues to increase, while the gas mass flow $\left(q_{m}^{*}\right)$ retain a same date;

Thirdly. change air pressure value $\left(P_{i n}\right)$, and repeat steps.

3) Analysis of results. Respectively, at different air pressure $(100 \mathrm{KPa}, 150 \mathrm{KPa}$ and at $200 \mathrm{KPa}$ or) conditions of experiment, record the gas mass flow (in $\mathrm{kg} / \mathrm{s}$ ) at different backpressure signal (in $\mathrm{KPa}$ ), the experimental data in Table I below:
TABLE I. BACK PRESSURE AND GAS MASS FLOW RATE UNDER DIFFERENT AIR PRESSURE

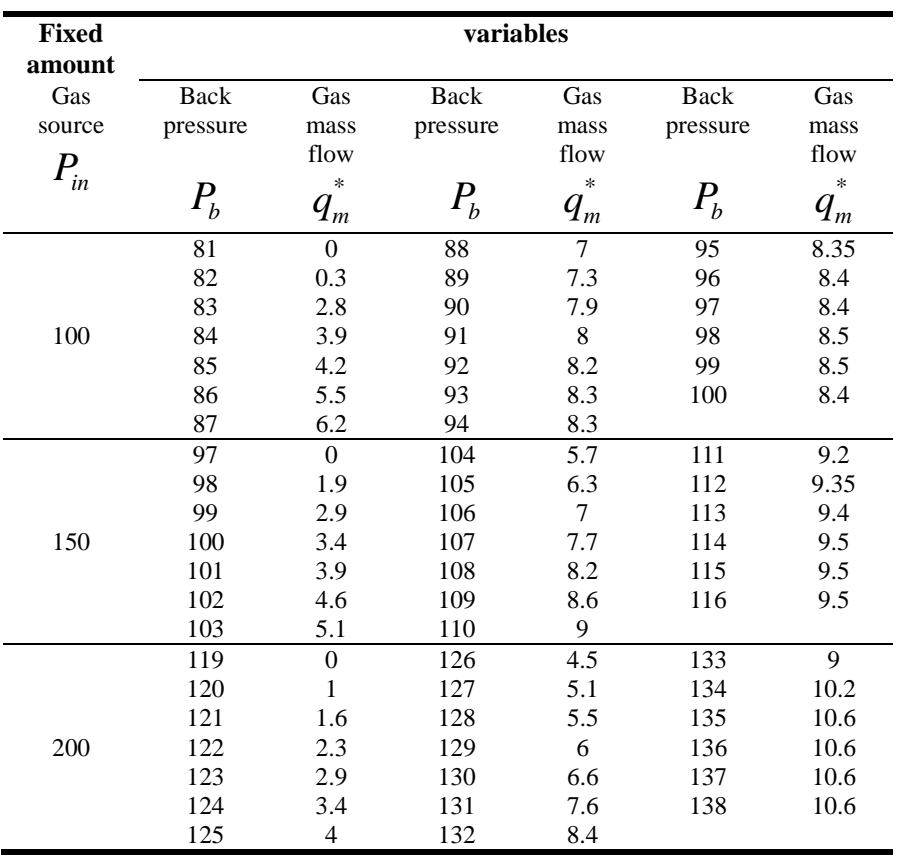

According to the combined force formula, each back pressure corresponds to a combined force, which can be obtained under different air pressures, the relationship between gas mass flow and the forces generated by the respective diaphragm amplifier as shown in the below 3

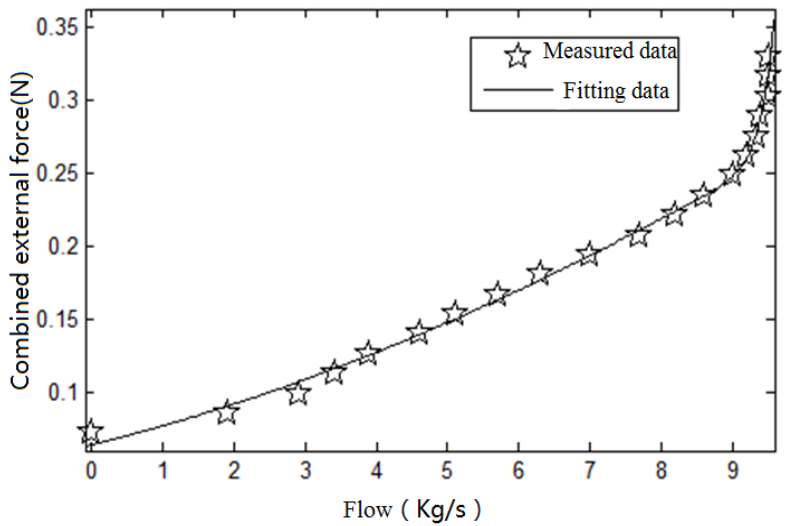

FIGURE III. (a). THE CURVE OF THE FLOW RATE AND THE EXTERNAL FORCE WHEN THE GAS PRESSURE IS 100KPA 


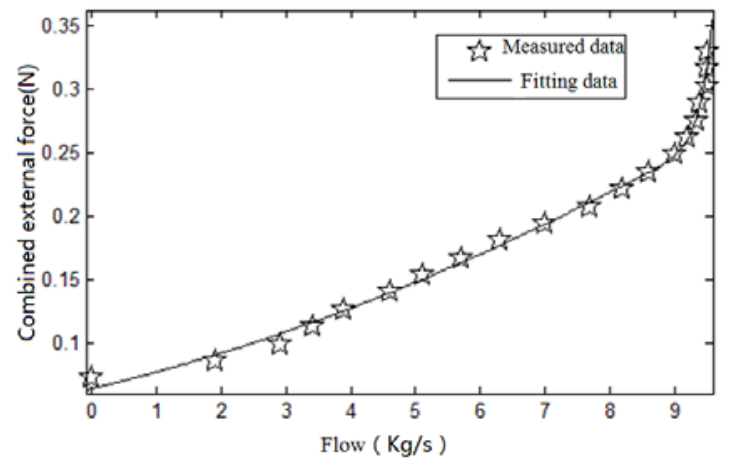

(b). THE CURVE OF THE FLOW RATE AND THE EXTERNAL FORCE WHEN THE GAS PRESSURE IS 150KPA

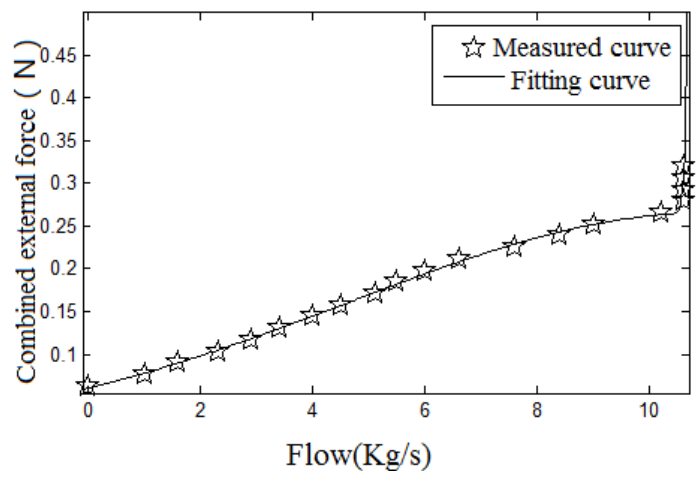

(c). THE CURVE OF THE FLOW RATE AND THE EXTERNAL FORCE WHEN THE GAS PRESSURE IS 200KPa

From the above graph, we can draw the following approximate conclusions. (a) the gas mass flow rate $\left(q_{m}^{*}\right)$ and the combined force $(F)$ are proportional.

(b) when the combined force $(F)$ increases to a certain extent, the gas mass flow $\left(q_{m}^{*}\right)$ no longer increases.

(c) under different air pressure, the combined force $(F)$ and gas mass flow $\left(q_{m}^{*}\right)$ are different proportional relationship.

Finally, from the above conclusions as well as the linear relationship between the gas mass flow $\left(q_{m}^{*}\right)$ and the equivalent orifice area $\left(S_{e}\right)$, we can conclude that the equivalent orifice area $\left(S_{e}\right)$ and the combined force $(F)$ are proportional relationship, and when the combined force increases to a certain extent, the equivalent orifice area $\left(S_{e}\right)$ is a constant value.

\section{Model Parameters IDENTIFICATION}

Installing the intelligent positioner to the actual valve forms a complete closed-loop valve control system, and at the same time we can also establish a complete control valve simulation model. Conduct open loop experiments for the actual valve and control valve simulation model respectively. Firstly, conduct an open-loop step experiment with control current signal from $0 \mathrm{~mA}$ to $1.16 \mathrm{~mA}$. When the control current is $1.16 \mathrm{~mA}$, the air control signal $(\mathrm{Pb})$ is large. then ensuring the force $(\mathrm{F})$ is much larger than the threshold value, and the nozzle and the damper of the pneumatic amplifier are fully open and the control valve is in the full inflated state. At this time, the equivalent orifice throttle area(Se) is determined by the maximum value of equivalent orifice throttle area(Max) . Constantly adjusting the maximum value of the equivalent area of simulation models Orifice, so that the actual valve position signal and the simulation of valve position signal are matching. This is the maximum equivalent orifice throttle area, and max is $1.45 \mathrm{e}-6$. As shown in Figure IV.

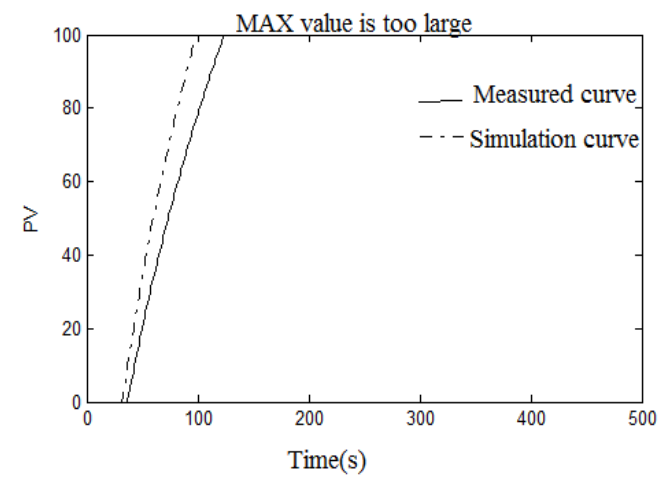

FIGURE IV. (a). THE COMPARISON OF MEASURED AND SIMULATED CURVES AS THE VALUE OF SE IS TOO LARGE

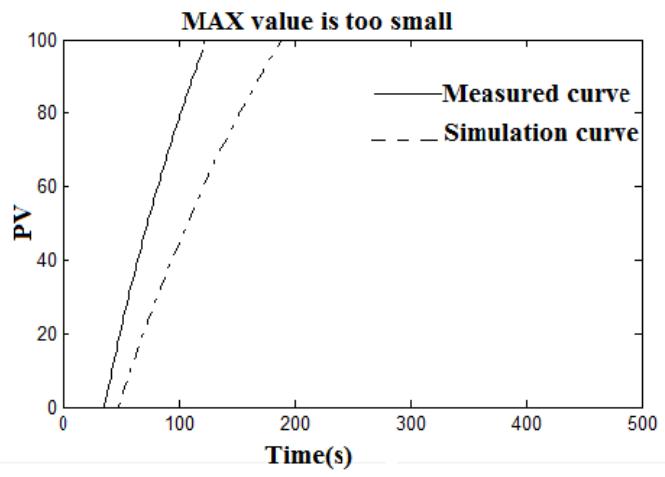

(b). THE COMPARISON OF MEASURED AND SIMULATED CURVES AS THE VALUE OF SE IS TOO SMALL

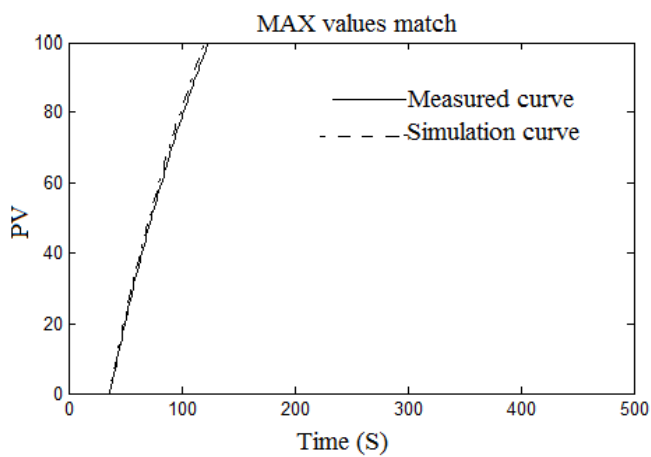

(c). THE COMPARISON OF MEASURED AND SIMULATED CURVES AS THE VALUE OF SE IS SUITABLE

Secondly, conduct an open-loop step experiment whose control current signal vary from $0 \mathrm{~mA}$ to $0.4292 \mathrm{~mA}$. when the 
control current is $0.4292 \mathrm{~mA}$, the control air pressure signal is very small, we can ensure that the combined force $(F)$ is much smaller than the threshold value, so the nozzle and the damper of the pneumatic amplifier are not fully open and the control valve is not in full inflated state, then the equivalent orifice restriction area (Se) is $\mathrm{kF}$. Constantly adjusting the value $\mathrm{k}$ of the simulation model, so that the actual valve position signal and valve position signal simulation are matching. The value scaling factor $\mathrm{k}$ is the proportion coefficient of the throttle orifice area and combined force and $\mathrm{k}$ is $0.275 \mathrm{e}-11$. As shown in Figure V.

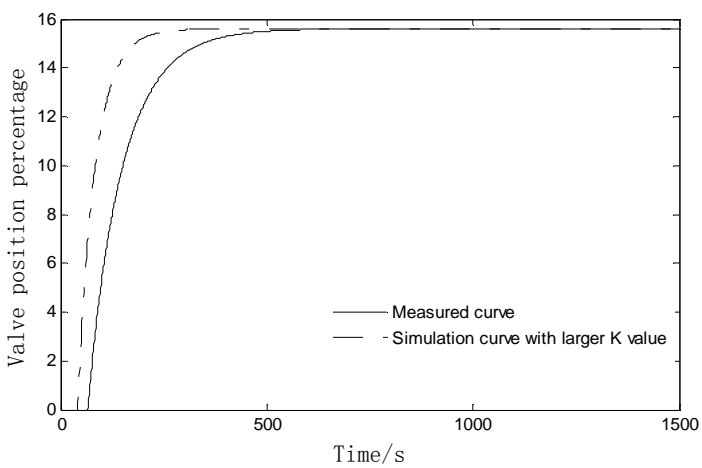

FIGURE V. (a). THE COMPARISON OF MEASURED AND SIMULATED CURVES AS THE VALUE OF K IS TOO LARGE

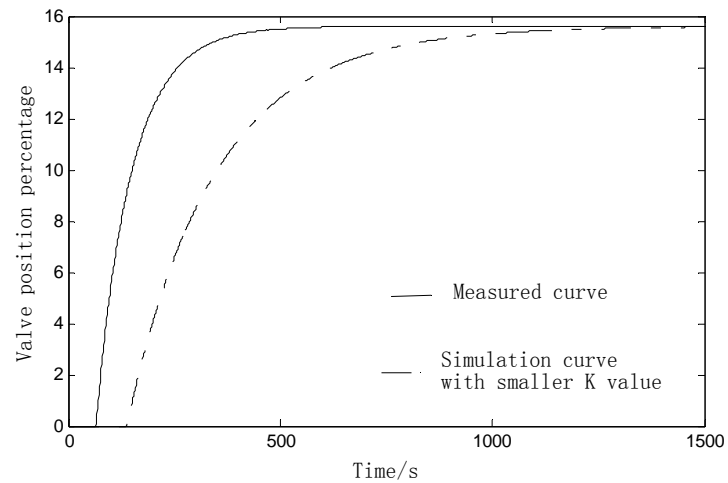

(b). THE COMPARISON OF MEASURED AND SIMULATED CURVES AS THE VALUE OF K IS TOO SMALL

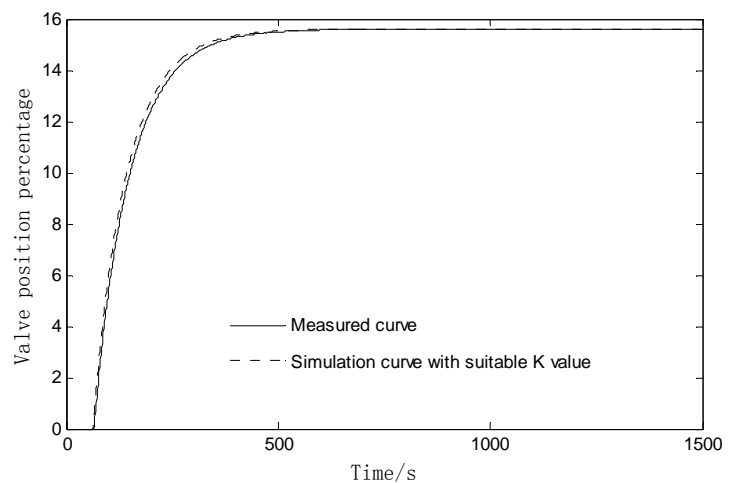

(c). THE COMPARISON OF MEASURED AND SIMULATED CURVES AS THE VALUE OF K IS SUITABLE
Finally, since the equivalent orifice restriction area $\left(S_{e}\right)$ is a continuously change amount (the equivalent orifice restriction area is a continuous function of the model), therefore, the combined force increase threshold valve equivalent throttle area the maximum value (Max) and the proportional coefficient $(\mathrm{k})$ ratio $(\mathrm{Max} / \mathrm{k})$, found $\mathrm{k}=5.31 \mathrm{e} 5$.

\section{EXPERIMENTAL VERIFICATION}

\section{A. The Design of Verification Scheme}

Pneumatic amplifier is universal pneumatic positioner amplifying part. There is no way to verify the accuracy of the model with a single component, therefore, adding the $\mathrm{E} / \mathrm{P}$ conversion unit in the universal locator to verify the accuracy of model. The structure diagram is shown in Figure VI:

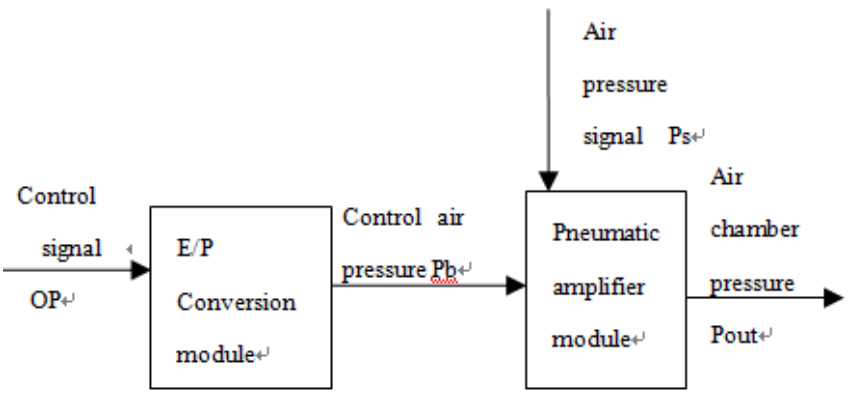

FIGURE VI. STRUCTURE DIAGRAM OF MODEL VALIDATION

\section{B. Analysis the Verification Result}

The actual factory parameters of regulating valve, and the physical picture are shown in Table II as follows:

TABLE II. ACTUAL CONTROL VALVE FACTORY PARAMETERS AND PHYSICAL PICTURE

\begin{tabular}{|l|l|l|}
\hline Model & ATS \\
\hline Valve body & ZG251 & \\
\hline The actuator & MF2D-16B \\
\hline Trip & $16 \mathrm{~mm}$ \\
\hline $\begin{array}{l}\text { Spring range } \\
\text { The supply } \\
\text { pressure }\end{array}$ & $400 \mathrm{KPa}$ & \\
\hline
\end{tabular}

After conducting multiple sets of open loop Step experiments, we have found that the results are generally same. We took the following open-loop current control $0.4524 \mathrm{~mA}$ 0mA-0.4524mA a step test as an example for analysis. comparison of the results are shown in Figure VII and Figure VIII: 


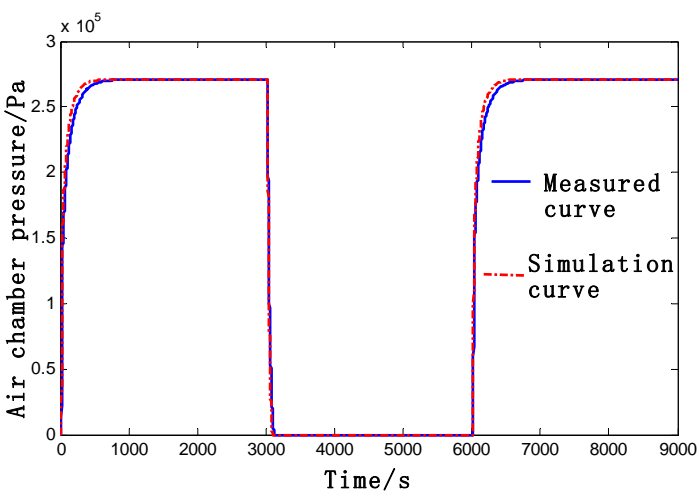

FIGURE VII. COMPARISON OF SIMULATED AND MEASURED AIR PRESSURE

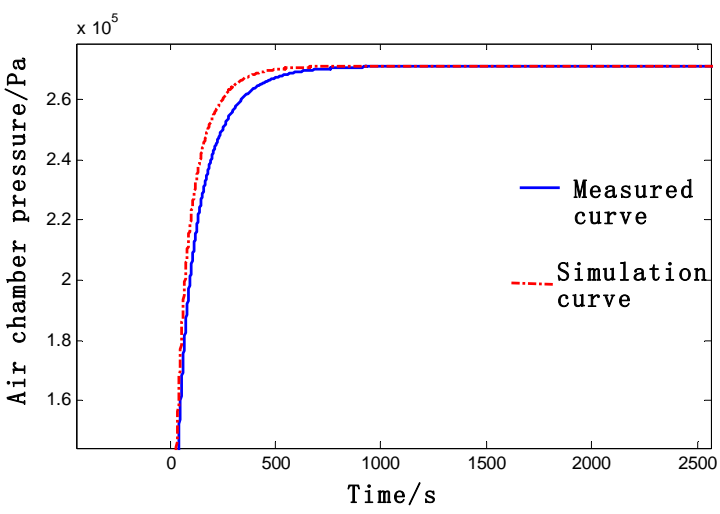

FIGURE VIII. SIMULATION AND MEASUREMENT OF ATMOSPHERIC PRESSURE SIGNAL DETAILS OF THE ENLARGED DIAGRAM

Based on the experimental results, the experimental data is analyzed and the dynamic performance indexes are calculated. The results are shown in Table III:

TABLE III. COMPARISON OF DYNAMIC PERFORMANCE INDEXES

\begin{tabular}{lccc}
\hline \multirow{2}{*}{ Indicators } & \multicolumn{3}{c}{ Signal Type } \\
\cline { 2 - 4 } & Measured sign & Simulation & The percentage of error \\
\cline { 2 - 4 } The final value of the & 270.3 & 270.3 & $0 \%$ \\
pressure response /KPa & 6.46 & 6.1 & $5.57 \%$ \\
The rising time /S & 9.68 & 9.62 & $0.62 \%$ \\
The adjusting e time /S & 40899 & 38087 & $6.85 \%$ \\
ISE value & &
\end{tabular}

Where in, the final value of the pressure response means the ultimate stability value, and its unit is $\mathrm{KPa}$. The rising time means the response time required to rise from $10 \%$ to $90 \%$ of the final value. The adjusting time means the response arrives and maintained at the final value the minimum time required within 5\%. ISE value means found plenum pressure simulation chamber pressure signal and the response signal and the final value of the integral square error. As can be seen from the above table, the maximum error percentage is $6.85 \%$, and the error is within the acceptable error range of the model. The validity of the proposed model and the identification parameters are verified. We conducted the same experiment with different control valve, different pressure parameter, different actuator, and finally have drawn the same conclusion.

\section{CONCLUSION}

In this paper, the typical pneumatic amplifier mass flow mechanism model is established, and the method of parameters identification is proposed. After studying and analysising the working principle and structure characteristics of the pneumatic amplifier in this paper, we put forward the mass flow mathematical model of pneumatic amplifier. Furtherly, according to the characteristics of gas flow and gas mass flow model, the equivalent throttle area sub-model contained in pneumatic amplifier mass flow mathematical model is established by analysis of experimental data, and the parameters of the model are identified. Finally, the model and identified parameter are verified based on control valve experimental platform. The verification results showed that the maximum error percentage is $6.85 \%$, and the established model in this paper and the identified parameters are valid.

\section{REFERENCES}

[1] Du H, Wei J H , Feng R L . Modeling,simulation and experimental research on pressure tracking vavle[J]. Journal of Zhejiang University(Engineering Science) 2012,46(06) : 1034-1042.

[2] Zhang Q M. Modelling of linear system for air pressure control by using pneumatic diaphragm vavle[J]. Computer Measurement \& Control. 2013,21(07):1942-1945.

[3] Bai Q Y, Wang R. Rotating valve power steering gear Improved Mathematical Modeling[J]. Science and Technology Innovation Herald. 2012,10(75):133-135.

[4] J. Wang, D.J.D. Wang, P.R. Moore, et al. Modelling Study, Analysis and Robust Servo Control of Pneumati Cylinder Actuator Systems[J]. Control Theory and Applications, 2001, 148(1):35-41.

[5] A.Messina, N.I.Giannoccaro, A. Gentile. Experimenting and modelling PWM- based pneumatic actuators [J]. Mechatronics, 2005, 15(7): 859-881.

[6] LI Q R,LAI Q F. Design and implementation of intelli-gent valve positioner based on HART. Protocol [J] Process Automation Instrumentation,2010,31 ( 6 ):55- 57.

[7] TANG G X,HU S H. Study of Pneumatic Amplifier of New Smart Valve Positioner[J]. Automation \& Instrumentation,2010(06):15-17.

[8] Cai M. Design of New Type of Domestic Smart Valve Positioner[J].Process Automation Instrumentation, 2010,44(7):73 79.

[9] Xu W C, Zhang SH H. Research on Flow Rate Characteristics of Tubes[J]. Chinese Hydraulics \& Pneumatics, 2013, 05:52-57.

[10] SI J , Wang Y SH, Shi W X. An Approach to Critical Pressure Ratio b and Its Flow-rate Formulas for Pneumatic Valve[J]. Hydraulics Pneumatics \& Seals, 2011, 31 (02) : 47-51.

[11] Yang L H, Liu CH L, Ye Q. Study on discharge method for measurement flow rate characteristics based on heat- exchange[J]. Chinese Journal of Scientific Instrument,2006,27(z1) : 41-43.

[12] ZHANG S H , XU W C. Study on Critical Pressure Ratio (b) by Determinations Of Effective Area (S and A)[J]. Hydraulics Pneumatics \& Seals, 2013,03:62-65.

[13] HU H M,CUI L SH,WANG CH,et al. Experimental study on critical back- pressure ratio of sonic nozzle at low Reynold number[J]. Chinese Journal of Scientific Instrument, 2012,33(4) : 737-742.

[14] LI CH H,PENG X F,LI Q M,et al. Flow characteristics of a supersonic nozzle for micro flow measurement [J]. Journal of Thermal Science and Technology, 2008,7(3): 11- 14

[15] Wang W, Chen F G, Ming Y, et al. Design of Plug Contour Line for Single- seat Control Valve[J]. Fluid Machinery, 2016, 44(05):37-42. 